\title{
CUERPOS QUE CAEN, CUERPOS QUE SIENTEN. ARCHIVO FAMILIAR, MEMORIA QUEER Y LENGUAJE HÁPTICO EN TRES DOCUMENTALES RECIENTES DE AMÉRICA LATINA
}

\author{
Guillermo Severiche \\ Fordham University \\ gseveriche@fordham.edu
}

\section{Resumen}

Este ensayo compara los elementos formales que comparten tres documentales latinoamericanos recientes: 108 Cuchillo de palo (dir. Renate Costa, Paraguay, 2010), Memories of a Penitent Heart (dir. Cecilia Aldarondo, Puerto Rico, 2016) y El silencio es un cuerpo que cae (dir. Agustina Comedi, Argentina, 2017). Tomando los aportes de Laura Marks y Vivian Sobchack, es posible afirmar que estos filmes apuestan por la capacidad audiovisual de recrear la presencia física de los sujetos ausentes mediante un lenguaje háptico y otras herramientas cinematográficas que reconstruyen una red afectiva pasada. Para ello, los filmes se valen de tres recursos distintivos: 1) el registro de objetos táctiles que pasan de mano en mano y que evocan una presencia física, 2) el uso de imágenes de archivo personal y 3) la intervención o experimentación de imágenes, ya sea de archivo o de la misma cámara de la directora, para evocar una memoria no recuperada.

Palabras clave: cine latinoamericano, el cuerpo, documental primera persona, archivo queer.

FALLING BODIES, FEELING BODIES. FAMILY ARCHIVES, QUEER MEMORY, AND HAPTIC LANGUAGE IN THREE RECENT LATIN AMERICAN DOCUMENTARIES

\section{Abstract}

This essay compares the formal elements shared by three recent documentaries from Latin America: 108 (dir. Renate Costa, Paraguay, 2010), Memories of a Penitent Heart (dir. Cecilia Aldarondo, Puerto Rico, 2016), and Silence is a Falling Body (dir. Agustina Comedi, Argentina, 2017). Based on Laura Marks and Vivian Sobchack's contributions, it is possible to affirm that these films recreate the physical presence of absent subjects by using haptic language and other cinematographic tools that reconstruct a past affective network. To do so, the films use three distinctive resources: 1) the capture of tactile objects that pass from hand to hand and that evoke a physical presence, 2) the use of images from personal archives and 3) the intervention or experimentation of images, either from the archive or from the director's own camera, to evoke an unrecovered memory.

KEYWORDs: latin american cinema, the body, first-person documentary, queer archive.

DOI: https://doi.org/10.25145/j.clepsydra.2021.21.09

Revista Clepsydra, 21; marzo 2021, pp. 187-202; ISSN: e-2530-8424 
En el 2010, la directora paraguaya Renate Costa presenta su primer documental, 108 Cuchillo de palo, una investigación sobre la vida íntima de su tío fallecido en 1999, Rodolfo Costa. En el film, Costa dialoga largamente con su padre, Pedro, y entrevista a vecinos, amigos y colegas de su tío, a la vez que indaga en archivos policiales para explorar los vestigios de la persecución y tortura de la comunidad LGBT en Paraguay durante la dictadura de Alfredo Stroessner (1954-1989). Seis años después, en el 2016, la directora puertorriqueña Cecilia Aldarondo da a conocer su ópera prima, el documental Memories of A Penitent Heart. En el mismo, ella recoge fotografías, videos caseros y objetos personales de sus parientes para presentar la vida íntima de su tío Miguel Dieppa, actor radicado en Nueva York y fallecido por complicaciones derivadas del sida en la década de los ochenta. Aldarondo inicia una investigación sobre su pasado familiar a través de entrevistas a su madre, amigos de la familia, amigos de su tío y Robert, la pareja de Miguel, ahora convertido en monje católico. Finalmente, en el 2017, la directora argentina Agustina Comedi estrena su primer documental, El silencio es un cuerpo que cae. En el film, Comedi revela la vida oculta de su padre, Jaime, fallecido en un accidente en 1999. Ella entrevista sobre todo a colegas de su padre, militantes de izquierda, y a amigos cercanos pertenecientes a la comunidad LGBT. Con menor o mayor reserva, los entrevistados presentan a Jaime como un hombre gay viviendo su sexualidad con cierta plenitud durante los ochenta hasta que decide cambiar su vida, casarse y formar una familia. Comedi intercala estas entrevistas con videos caseros de reuniones y viajes familiares filmados por su propio padre.

Al observar las sinopsis de estos documentales, las similitudes se hacen evidentes. Se trata de tres óperas primas dirigidas por mujeres en las que se investiga la historia secreta de un familiar fallecido a modo de pesquisa detectivesca. Esta historia secreta, ya sea una vida pasada abandonada o una muerte misteriosa, revela la tensión homofóbica entre un hombre homosexual y su entorno familiar. A su vez, la familia, primer estrato de un sistema social mayor, pone en evidencia los mecanismos opresivos de la Iglesia católica, de los gobiernos dictatoriales o, incluso, del discurso patriarcal y heteronormativo en los partidos políticos de izquierda. Los tres documentales, en mayor o menor medida, recurren también a las mismas herramientas para recabar información y evidenciar las tensiones del familiar ausente y su entorno: entrevistas, archivo personal (videos caseros, fotografías, etc.) y la presencia física de la directora (frente o detrás de la cámara). Es más, las voces de las directoras, en los tres casos, ponen en tensión un yo-narrador que se entrelaza de diferentes modos con las de los familiares fallecidos, un yo-narrado, quienes por momentos asumen la voz narrativa principal. Esto evidencia un interés diverso pero común en explorar una historia trágica pasada que sirva como reflejo de una búsqueda personal, íntima, autobiográfica.

Este ensayo, no obstante, analiza de forma comparativa los elementos formales que comparten estas películas para dar cuenta del rol que cumple la corporalidad tanto en el plano estético como en el conceptual. Valiéndome de los aportes de Laura Marks y Vivian Sobchack, sostengo que, más allá de las evidentes similitudes, las tres películas comparten recursos formales para apelar a la sensibilidad del espectador. Las tres apuestan a la capacidad audiovisual de recrear la presen- 
cia física de los sujetos ausentes mediante un lenguaje háptico y otras herramientas cinematográficas que construyen una red afectiva pasada pero aún persistente. Es decir, que los familiares fallecidos cuya historia de otredad sexual fue violentamente desplazada por sistemas dominantes reaparecen no como "fantasmas» sino como sujetos encarnados, todavía latentes para la directora y personas cercanas. Para ello, los filmes se valen de tres recursos distintivos: 1) el registro de objetos táctiles que pasan de mano en mano y que evocan una presencia física, 2) el uso de imágenes de archivo personal y 3) la intervención o experimentación de imágenes, ya sea de archivo o de la misma cámara de la directora, para evocar una memoria no recuperada en el plano audiovisual.

En su estudio The Skin of the Film, Laura Marks se enfoca en clasificar y analizar los medios formales con los que películas y videos interculturales apelan al conocimiento no visual, al conocimiento corpóreo y a las experiencias de los sentidos del tacto, el olfato y el gusto en los espectadores (2). Si bien solamente el film de Aldarondo se ubica en el campo del cine intercultural, es posible establecer entre los tres documentales un objetivo compartido, que Marks identifica en su estudio: la arqueología de una historia desaparecida. Ella postula que el trabajo de excavación que se realiza en los filmes interculturales constituye, en primer lugar, una actividad deconstructiva, ya que deben desmantelar los discursos históricos coloniales que enmarcan las historias de las minorías. Esto es necesario para que dichas minorías puedan contar su historia en sus propios términos (25). Esta actividad, según Marks, conlleva un quiebre formal y una suspensión del sentido, una suerte de silencio que abre fisuras en el discurso histórico dominante y que deja ver el hecho trágico de que las historias perdidas están perdidas para siempre (25). Ahora bien, tales fisuras son también altamente productivas porque en ellas se ubica una voz emergente y se apela a otras formas de conocimiento cultural. Marks identifica este momento como un descubrimiento: «This process of discovery is like scavenging in a tide pool for the small, speaking objects that are briefly revealed there before the water rushes in again». (26) La cualidad evasiva de este discurso que da cuenta de una memoria por siempre perdida dificulta su conceptualización universal, una explicación que la revele completamente. Sin embargo, al discriminar los recursos formales que se desvían de una primacía de lo óptico hacia una valorización de lo táctil, es posible notar en los tres documentales la búsqueda de una memoria queer que sobrevive a la opresión homofóbica del círculo familiar, religioso y político.

El registro de una memoria colectiva atravesada por el trauma no es nuevo en la producción documental latinoamericana reciente, más específicamente, en la argentina. Papá Iván (2000), de María Inés Roqué, o Los rubios (2003), de Albertina Carri, son algunos ejemplos icónicos de un recorrido hacia el pasado familiar, en estos casos, en el contexto posterior a la última dictadura militar (1976-1983). Según Jens Andermann, basándose en Marianne Hirsch, aquello que diferencia a la nueva generación de documentalistas no es un estado de "posterioridad» a los eventos ocurridos, sino la relación que se establece con aquello que se conmemora. La posmemoria, como lo denomina Hirsch, tiene que ver con una investidura imaginativa sobre lo que se recuerda, una apropiación creativa (107). Según Belén Ciancio, los filmes de la posmemoria argentina «ponen en juego una corporalidad que 
bordea el límite de la representación, en tanto remite como imagen virtual a un cuerpo desaparecido" (236). Si bien solo 108 y El silencio... incorporan en sus relatos el contexto de dictaduras militares, los tres documentales que comparo en este artículo ejercen una memoria inventiva en la que se busca de diversos modos restaurar un cuerpo ausente.

La reinvención de la memoria comprende también una fuerte evidencia de la voz autorial, de un yo que organiza el relato y lo presenta. Pablo Piedras afirma que la irrupción de la primera persona en el documental argentino, particularmente, es producto de una situación de poscrisis. En este contexto «se reconfigura el campo artístico a partir de la emergencia de la experiencia y de la subjetividad como ejes necesarios para sostener un discurso sobre el mundo, cuando parecen encontrarse en trance los grandes relatos ideológicos, sociales, económicos y políticos» (29). Para Piedras, lo más importante de la transformación que genera la irrupción de la voz autorial en el documental, en Argentina y en otras regiones de América Latina, se podría agregar, tiene que ver con el pacto establecido con el espectador. Más particularmente, las proposiciones que presentan estos documentales, apunta Piedras, son parciales, tentativas y provisorias, pero arraigadas en la memoria cercana de quien enuncia (30). Esto permite pasar de un campo personal a uno colectivo en el que se resuelva o reorganicen nuevas identidades (políticas, sociales, culturales y de género) (31). Es decir, que se establece una relación dinámica entre el plano privado y el público: se utiliza el primero para modificar el segundo, y el segundo para entender el primero. Afirma Piedras:

estas obras siguen buscando en la historia pública y compartida las respuestas para comprender las historias personales o familiares y, de manera inversa, mantienen la intención explícita de que las exploraciones del mundo privado produzcan efectos en hechos de la esfera pública o sirvan para explicarlos (167).

La dinámica entre lo privado y lo público resulta altamente evidente en el film de Renate Costa, 108 Cuchillo de palo. Ya desde el título, el documental cuestiona el tabú social existente y el pasado político en Paraguay alrededor del número 108. Fiore Urízar y Holt explican que este número "es un término despectivo que usan los paraguayos hacia los hombres gay, un insulto que tiene sus raíces en la primera de las varias listas de homosexuales presos (y torturados) creada por el gobierno de Alfredo Stroessner» (244). En el film, Costa indaga en la vida de su tío, cuyo cuerpo apareció muerto de manera misteriosa en su departamento, sin ropa y sin sus pertenencias. Sin embargo, también investiga los vestigios sociales de la opresión hacia la comunidad LGBT durante las décadas pasadas al descubrir que su propio tío fue encarcelado y reportado en una de las listas. Costa conversa largamente con su padre mientras él lleva su vida cotidiana en el taller de herrería - una herencia familiar-y dispone frente a la cámara una diferencia irreconciliable entre generaciones. Según Eva Romero, 108 Cuchillo de palo representa un quiebre de los ideales nacionalistas más puristas de lo paraguayo al establecer «contramemorias» queer, paraguayas y clandestinas. Estas son historias que el Estado y el discurso religioso han intentado borrar (104). Romero agrega: «In Cuchillo there are two temporalities with 
two different power structures that enter into its reason: the power structure of the military dictatorship and the power structure of the new democratic order» (104). Se podría identificar a la directora, quien aparece en escena constantemente, como una temporalidad de la nueva democracia, mientras que su padre representaría a la de la dictadura. Por tanto, el film hace de esta tensión un acto performativo, un acto de denuncia, para dialogar y repensar las estructuras ideológicas que han llevado a la tortura de cientos de personas LGBT y que aún perviven en la sociedad contemporánea.

Ahora bien, de las tres películas analizadas en este ensayo, 108 es quizás la que menos utiliza un lenguaje háptico para recrear a la persona ausente. De todos modos, el plano afectivo es quizás el que evidencia el legado de Rodolfo como aún persistente. Las entrevistas a los allegados del tío de la directora, que incluyen la de una reconocida mujer transexual, ponen frente a la cámara ánimos de carińo, pena y frustración por la figura del amigo fallecido. Quisiera hacer énfasis en el uso de un documento público, la lista de hombres homosexuales encarcelados en 1982, que la directora recoge del archivo estatal y que utiliza y reinventa. Considero este objeto destacable no solo porque se constituye en un leitmotiv narrativo que impulsa a los entrevistados a hablar sino también porque el film despliega una transformación del archivo policial en archivo queer. Este documento se vuelve un disparador de recuerdos y afectos de una otredad sexual que vivió/vive bajo amenaza.

Basándose en Gilles Deleuze, Laura Marks reconoce en el cine intercultural el uso de objetos para excavar memorias personales y comunales que dan cuenta del movimiento entre culturas. Ella denomina este fenómeno recollection-object, un objeto irreduciblemente material que codifica la memoria colectiva (77). Lo importante de estos objetos, según Marks, es que condensan el tiempo en ellos mismos y que al excavarlos expandimos el tiempo hacia afuera (77). La autora enfatiza que el significado de estos objetos no se codifica metafóricamente sino a través del contacto físico (80). Muchas de las películas que analiza invitan al espectador a percibir «físicamente» el objeto que despierta una memoria colectiva enterrada por los discursos coloniales:

I suggest that objects are not inert and mute but that they tell stories and describe trajectories. Cinema is capable not only of following this process chronologically but also of discovering the value that inheres in objects: the discursive layers that take material form in them, the unresolved traumas that become embedded in them, and the history of material interactions that they encode (80).

Se podría pensar el archivo policial que Costa recupera de la burocracia estatal y que luego comparte con amigos de su tío fallecido (algunos también nombrados en la lista) como una suerte de objeto que paulatinamente adquiere un valor afectivo colectivo. El documental da cuenta del momento en que se extraen las hojas de los archiveros y se busca el nombre del tío junto a los de decenas de personas. Costa consigue una copia que lleva consigo y comparte, de mano en mano, con los entrevistados. Si bien no podría decirse que existe una invitación a percibir "físicamente» la naturaleza material del objeto, sí hay una referencia óptica a la manipulación de 

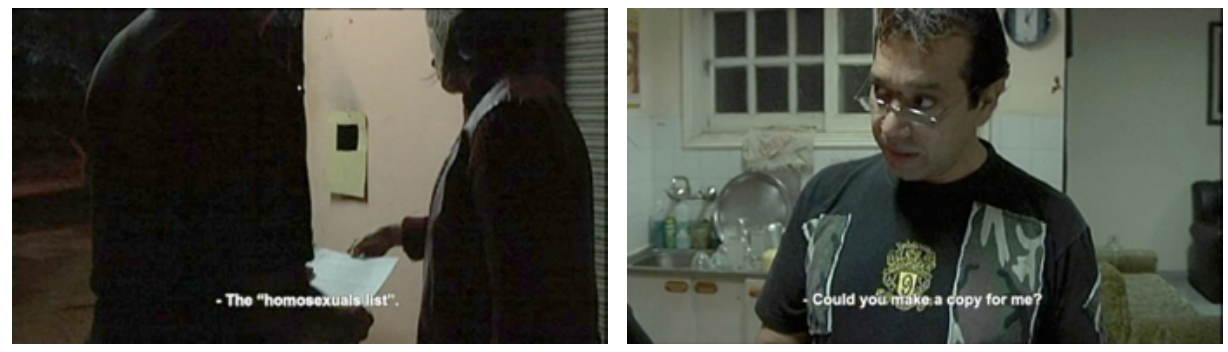

Figs. 1 y 2: Utilizando la «lista de homosexuales» para despertar recuerdos en 108 Cuchillo de palo.

un documento sepultado en el archivo estatal. Lo que el film presenta, más bien, es la transformación de esta lista de un símbolo de humillación, castigo y tortura a un disparador de recuerdos, afectos y anécdotas propias de la comunidad LGBT de ese entonces. El film captura, en este acto de pasar de mano en mano, la apropiación de la herramienta opresiva del Gobierno dictatorial por parte de los oprimidos para evocar una historia emotiva que aún pervive en ellos. Cabe mencionar que algunos prefirieron no ser nombrados ni aparecer frente a cámara. Uno de ellos cuenta que tuvo la lista en sus manos alguna vez y que la quemó hace mucho tiempo. Algunos le piden a la directora quedarse con el documento o recibir una copia.

Esta petición de los entrevistados remite a lo que Marks agrega sobre los recollection-objects como objetos que traen consigo un carácter aurático. Ella reformula la noción benjaminiana del aura de la siguiente manera: «Aura is the sense an object gives that it can speak to us of the past, without ever letting us completely decipher it. It is a brush with involuntary memory, memory that can only be arrived at through a shock» (81). Por más que se lo mire de cerca, agrega, no es posible descifrar la memoria que el objeto encierra y satisfacer nuestro intento de acercarnos a su tiempo y espacio.

En 108, las reacciones de los entrevistados al mirar y sostener el documento policial en sus manos podría interpretarse como un acto de curiosidad que busca deslindar los acontecimientos y las emociones que se encierran en su materialidad. Ya no se trata de un arma de tortura social utilizada bajo la dictadura, sino de un documento que da cuenta de la existencia pasada de una comunidad, de una experiencia (tortuosa) compartida con otros quizás ya del todo desaparecidos. Al tener el documento, muchos de ellos pueden recordar más detalles de su encierro o de las historias de semejantes quienes han muerto o cuyo contacto ya han perdido. Uno de ellos, quien decidió no dar su cara ni su nombre, cuenta luego de ver la lista: "Yo me acuerdo que la primera vez que salí [de la cárcel] me fui a una fiesta y no pude estar en esa fiesta. [...] Tenía miedo. Qué sé yo. No podía ver policías. Yo, así como experiencia, lo borré de mi mente». A otro entrevistado, quien ve su nombre junto al de Rodolfo Costa en la lista de homosexuales apresados, la directora le pregunta si su tío recibía visitas. Él responde: «Muy poco. Más que nada venía gente amiga de él a traerle cosas. Inclusive él no quería que su familia se entere. Gente cercana 
a él eran los que venían a verle. Yo me acuerdo». Ya se trate de emociones tortuosas o de evidencia de una red de apoyo, el documento despierta recuerdos que el documental registra como una suerte de un nuevo archivo que se ubica en el plano de los afectos de una comunidad borrada de la historia oficial.

El valor que adquiere este documento público en el film de Costa, junto al de otros objetos en los documentales de Aldarondo y Comedi, se relaciona con lo que Ann Cvetkovich denomina un "archivo de sentimientos» (archive of feelings). Es decir, los filmes muestran, a través de estos objetos, un material que da cuenta de una experiencia afectiva codificada no solo en su contenido, sino también en las prácticas que rodean su producción y recepción (7). Refiriéndose en particular a fotografías u objetos personales, Cvetkovich afirma que este material de archivo adquiere valor incalculable al tratarse de evidencia poco convencional de la historia de las culturas gay y lesbiana. Frente a la violencia invisibilizadora de la historia oficial, estos objetos emulan la naturaleza clandestina y evasiva de la comunidad de la que surgen. Ella agrega:

Forged around sexuality and intimacy, and hence forms of privacy and invisibility that are both chosen and enforced, gay and lesbian cultures often leave ephemeral and unusual traces. In the absence of institutionalized documentation or in opposition to official histories, memory becomes a valuable historical resource, and ephemeral and personal collections of objects stand alongside the documents of the dominant culture in order to offer alternative modes of knowledge (8).

En este sentido, sostengo que el valor preponderante del documento policial en 108 Cuchillo de palo se da, sobre todo, en el plano afectivo que se despliega al escuchar lo que los entrevistados recuerdan al tenerlo en sus manos. Por su parte, en Memories of a Penitent Heart, la intimidad y privacidad de los objetos que se muestran en el film ponen en evidencia una historia aún más elusiva que la del documental de Costa. En su investigación, Cecilia Aldarondo recoge objetos varios de la historia íntima de su tío Miguel Dieppa. Desde su salida de Puerto Rico hasta Nueva York, Miguel (rebautizado Michael por él mismo) deja documentos y objetos personales que salen a la luz en el film: cartas, fotografías, videos y sus propios textos literarios. Según Vidal-Ortiz, es el mismo Miguel quien construye la narrativa del documental, de su propia dualidad que no encuentra resolución, a través de los objetos que codifican una historia pasada (422).

En tomas sucesivas, Aldarondo decide filmar los artículos personales que recolecta agrupados sobre un fondo negro. A veces selecciona uno y lo registra con cuidado en tomas más largas. Estas enfatizan, claramente, no solo el significado emocional de los objetos (como se ve en la entrevista a Robert, pareja de Miguel), sino también la manipulación real por parte de Miguel. Entre estos objetos, destaca su billetera, cuyo contenido Aldarondo explora en varias tomas. De allí extrae fotografías y otros pequeños objetos que también muestra utilizando el mismo fondo negro. Es posible notar un uso cotidiano en el cuero gastado de la billetera. También resulta destacable una fotografía de Miguel cuya mitad fue cortada por él mismo, según comenta Robert. Aldarondo recompone la otra mitad de la fotografía 

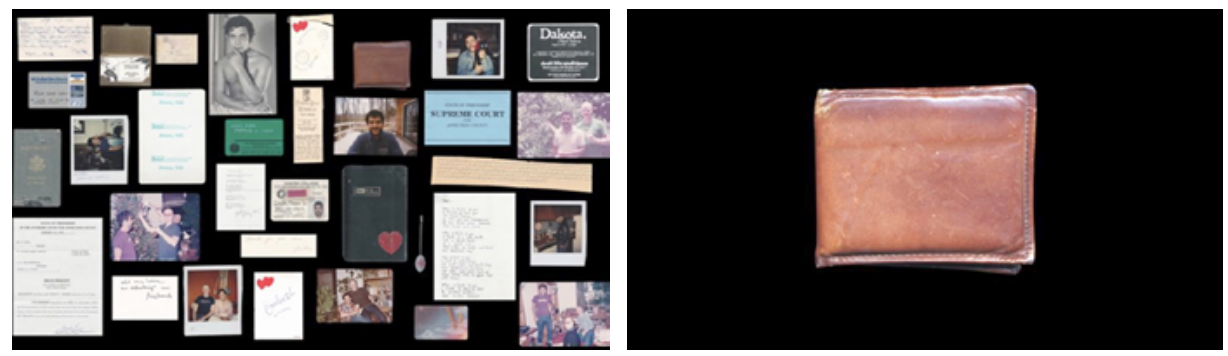

Figs. 3 y 4: Objetos personales de Miguel Dieppa dispuestos sobre fondo negro en Memories of a Penitent Heart.

y muestra que quien fue eliminada de la imagen fue su madre. Otros objetos son una pulsera y una identificación de Miguel emitida por el hospital. Aunque todo esto sea registro óptico, en estas tomas el film de Aldarondo demuestra un interés enfático por registrar la cualidad material de los objetos que recoge. Es decir, no solo se habla de ellos en las entrevistas y en la voz en off, sino que se los filma con detalle para evocar una presencia perdida aún evidente en las marcas físicas inscriptas en su materialidad. Al desplegar los objetos en tomas de fondo negro, el film sugiere una invitación a percibir específicamente dicha materialidad, a "tocar» los objetos pertenecientes a Miguel Dieppa. En este caso, no solo los entrevistados tienen la oportunidad de tomar los objetos en sus manos, sino que se invita a los espectadores a "percibirlos", ya que se disponen frente a nuestros ojos para una exploración más detenida, de carácter táctil. Miguel Dieppa se vuelve una presencia física más cercana. Como afirma Marks, «To touch something one's mother, one's grandparents, or an unknown person touched is to be in physical contact with them» (112).

Siguiendo a Marks, puede decirse que tanto los objetos personales de Miguel Dieppa como los videos familiares que Aldarondo recoge y organiza en su documental son elementos que viajan con las personas y que por ende también registran y codifican un desplazamiento cultural: «Intercultural cinema moves through space, gathering up histories and memories that are lost or covered over in the movement of displacement, and producing new knowledges out of the condition of being between cultures» (78). Otra de las evidencias de este desplazamiento, que pone de relieve las tensiones interculturales, así como las homofóbicas y generacionales, son los videos caseros y fotografías familiares utilizadas con frecuencia por Aldarondo. Según Elspeth kydd, el valor de los videos caseros no solo se da dentro del marco familiar, sino que también reflejan otras funciones ideológicas, más grandes, en particular agrupamientos sociales y afiliaciones a la comunidad imaginada de una nación (191). A su vez, Roger Odin observa el potencial de estos videos para dar cuenta de un discurso histórico fuera de la historia oficial:

Family filmmakers are involuntary endotic anthropologists; they film those moments of life that professionals ignore. Official reports fail to document entire aspects of society. Home movies are sometimes the only records of some racial, 
ethnic, cultural, social communities marginalised by the official version of history. Even if these films do not recount the entire history and often show what the community sanctions, these films represent important documents (citado por Kydd 195).

Este último punto es importante para observar el calibre documental que posee el uso de videos caseros y fotografías personales de Miguel Dieppa y de su madre (abuela de la directora) que aparecen en el film. En varias secuencias, Aldarondo contrapone las opiniones de los allegados, amigos y el amante de su tío Miguel con lo que dicen su propia madre (hermana de Miguel) y amigos cercanos de la familia Dieppa para dar cuenta de una distancia entre ellos, ya sea ideológica o generacional. Sus puntos de vista difieren respecto a la vida y sexualidad de Miguel y a las dinámicas familiares de los Dieppa. Estas diferencias se transforman en registro visual cuando Aldarondo contrapone grabaciones y fotografías de Miguel en Nueva York (interpretaciones en el escenario como actor profesional, entrevistas hechas con canales locales, imágenes con amigos en reuniones, fotos con su pareja Robert, etc.) con videos caseros filmados por la madre de Miguel (reuniones familiares, niños en la casa, la iglesia, etc.). Justamente, el film sostiene como tesis una tensión irreconciliable que escapa a la intimidad familiar de los Dieppa y que remite al marco social de Puerto Rico. Milton R. Machuca-Gálvez identifica esta tensión: «an island marked by a colonial rule with immediate access to US modernity but firmly anchored by the weight of tradition, the geographic reality of the island amplifying a sense of isolation" (481). Los videos y fotografías se transforman en evidencia óptica de una dicotomía social irreconciliable.

Volviendo a un plano más íntimo, esta dicotomía, irresuelta en el mismo Miguel/Michael, también tiene una evidencia visual que utiliza la directora al colocar dos fotografías de su tío en el hospital: una junto a su madre y otra junto a su pareja. Un punto importante que surge del uso de estos archivos y que entra en contacto con la corporalidad de los sujetos ausentes se ubica en la materialidad misma del archivo. Las fotografías, así como el sinfín de videos caseros, remiten a un modo de captura anterior a la era digital y que evidencia un contacto más físico con la realidad que registra. En un icónico ensayo de principios de los noventa, Vivan Sobchack utiliza conceptos de la fenomenología existencial de Maurice Merleau-Ponty para observar las consecuencias que traen los cambios en las tecnologías de representación. Al insistir en la naturaleza corpórea (embodied nature) de la consciencia humana y la existencia corporal como premisa material de significación, Sobchack compara las tecnologías cinemáticas con las electrónicas. Según ella, las primeras ponen en evidencia la actividad existencial de la visión misma:

In its pre-electronic state and original materiality, [...] the cinematic mechanically projected and made visible for the very first time not just the objective world but the very structure and process of subjective, embodied vision -hitherto only directly available to human beings as that invisible and private structure we each experience as "my own." That is, the materiality of the cinematic gives us concrete and empirical insight and makes objectively visible the reversible, dialectical, and social nature of our own subjective vision (96). 
En cambio, el registro electrónico se desprende de las estructuras temporales y espaciales, de una materialidad como la del cine en $35 \mathrm{~mm}$ o del video casero de $8 \mathrm{~mm}$, por ejemplo. Desde la experiencia fenomenológica del espectador, ya no se vive un punto de vista o una situación visual como se percibe con las tecnologías cinemáticas. Según Sobchack, «electronic presence randomly disperses its being across a network, its kinetic gestures describing and lighting on the surface of the screen rather than inscribing it with bodily dimension» (104).

La cualidad más destacable de las tecnologías cinemáticas (los videos caseros de la familia Dieppa o los videos que recogió Aldarondo de la vida de su tío en Nueva York, por ejemplo) consiste en remitir a los espectadores a la dimensión corpórea de la actividad existencial de la visión misma. Quizás podría pensarse este uso de archivo visual como un acto restitutivo de una percepción cinematográfica actualmente abrumada por la imagen digital. Sin embargo, las advertencias de Sobchack permiten detenerse en la materialidad del registro para pensar el contexto de captura que queda registrado en la materialidad en sí. Es decir, las posibilidades de grabar que otorga la cinta y su conservación (el granulado, el difuminado de líneas, el rayado que denota el uso reiterado de una reproductora, etc.) evidencian de manera visualmente perceptiva un momento y lugar, un paso del tiempo, una manipulación. Y en todos estos hay cuerpos, un contacto físico o movimientos corporales que se vuelven fenomenológicamente más aprehensibles que en una imagen digital. Por lo tanto, los videos caseros no solo ofrecen un registro óptico de la existencia física de Miguel Dieppa, sino que también entregan, a través de su materialidad, una realidad en la que él existía físicamente. Su existencia carnal se vuelve más cercana no solo porque lo vemos en la imagen, sino porque la cinta misma hace del acto de mirar una visión aún más corpórea y subjetiva y nos arroja al contexto en que fue creada.

Lo mismo ocurre en las imágenes finales de 108 Cuchillo de palo, cuando la directora reproduce un video casero en el que se celebra el cumpleaños de la abuela. Por un breve momento, Rodolfo Costa aparece detrás de otras personas, tímido, incómodo. Tal como sucede en los filmes de Aldarondo y Comedi, la materialidad de la cinta da cuenta del paso del tiempo y de un uso que nuestra visión recoge de modo táctil o, dicho en palabras de Marks, desde una visualidad háptica. Según esta investigadora, la percepción háptica privilegia la presencia material de la imagen y emerge sobre todo en el cine que apela al contacto, a la relación corpórea entre el espectador y la imagen, y no a la discriminación visual de lo que se captura o a la identificación con las figuras (164). Si bien el uso de videos caseros recién descrito en Costa no remite a una visualidad háptica en sí, es posible poner énfasis en la materialidad del video que invita a un acercamiento más corpóreo. En este punto, Marks añade:

Both film and video become more haptic as they die. Every time we watch a film, we witness its gradual decay: another scratch, more fading as it is exposed to the light, and chemical deterioration, especially with color film. Video decays more rapidly than film, quickly becoming a trace, a lingering aroma with few visual referents remaining (172). 
En El silencio es un cuerpo que cae, por su parte, a la materialidad de la cinta de los archivos que recoge Comedi se le suma el hecho de que muchos de los videos caseros fueron filmados por su padre. Por tanto, lo que la cámara selecciona y captura es lo que él en persona decidió grabar. Aquí la cercanía con la presencia física de Jaime se vuelve todavía más estrecha. En su libro The Address of the Eye, Sobchack pone especial atención a la relación corpórea entre la visión del espectador y la del film, indicando la cualidad activa de ambos. Aquello que el film hace visiblemente, el espectador lo hace visualmente (271). Podría extenderse el argumento de Sobchack al uso de videos caseros grabados por el mismo Jaime para pensar no solo su presencia física detrás de cámara, sino también su "presencia» en nuestra visión como espectadores. Según Sobchack, la actividad del espectador no consiste en «recibir» lo visible como propio, sino más bien en aceptar otra visión junto a la propia. Ella explica:

I am not a mere bodily receptable for the film's visual address, but rather a hospitable host, allowing this other visual address temporary residence in $m y$ visible address, in $m y$ body. My visible hospitality, however, in no way denies my own visual address, my own possession of the premises we both presently share so as to significantly negotiate meaning (272).

Es decir, no se trata de mirar desde los ojos de Jaime, sino de interactuar desde una corporalidad propia que está alerta a una corporalidad ajena. Esta otra visión de Jaime que se atestigua en los videos caseros da cuenta de esa otra corporalidad ausente reconstruida a través de diferentes medios e interpelaciones.

Ahora bien, de entre las estrategias que Comedi utiliza para remitir a la figura de su padre se destaca la de la confección de imágenes no referenciales que aluden a una memoria perdida sin registro posible. En varias oportunidades, Comedi reutiliza las imágenes de los videos caseros al colocarles filtros, recortar escenas breves y repetirlas o modificar su luminosidad o color. Se trata de estrategias que distorsionan la referencia inicial de los videos. Por lo general, las intervenciones realizadas sobre las imágenes captadas por Jaime remiten a recuerdos aludidos en las voz en off de las entrevistas y que no tienen un registro visual.

Según Marks, a través de una arqueología de la imagen se puede descubrir que este tipo de imágenes no referenciales expresan una divergencia entre diferentes niveles de conocimiento, es decir, entre la historia oficial y la memoria privada, por ejemplo (31). Hay aquí un hueco, una fisura, una nueva historia que se crea en un lenguaje no del todo formulado, casi ilegible. Basándose en Deleuze, Marks denomina estas imágenes recollection-images:

A recollection-image embodies the traces of an event whose representation has been buried, but it cannot represent the event itself. Through attentive recognition it may provoke an imaginative reconstruction, such as a flashback, that pulls it back into understandable causal relationships (50).

Las recollection-images requieren de un reconocimiento atento (attentive recognition) por parte del espectador, que consiste en considerar al mismo como 
libre de recurrir a su propia memoria para participar en la creación del objeto en la pantalla (48). Es decir, el espectador es capaz de intervenir la imagen que de por sí no se vale de figuras reconocibles o referencias claras a través de un contacto con los propios recuerdos y sensibilidad. Esto es de vital importancia para Marks, porque el cine intercultural que investiga no se dedica a encontrar la verdad de un evento histórico, sino más bien a hacer que la historia revele lo que no se pudo decir (29). Por ello, Marks pone atención en aquellos videos y filmes que expresan una divergencia entre los «órdenes del saber», como por ejemplo la historia oficial y la memoria privada. Estos videos y filmes lo logran al yuxtaponer diferentes órdenes de imágenes, o utilizar imágenes y sonidos que no se corresponden entre sí:

To read/hear the imagen, then, is to look/listen not for what's there but for the gaps [...] to look for what might be in the face of what is not. Hence the importance of absent images, barely legible images, and indistinguishable sound in so many of these works (31).

A diferencia de los filmes de Costa y Aldarondo, el film de Comedi se vale en mayor medida de una dislocación de sonido e imagen o de la intervención visual sobre material de archivo. En primer lugar, Comedi utiliza su propia cámara y el registro de espacios vacíos y personas desconocidas al tiempo que se escucha el recuerdo de una persona entrevistada. Mientras la voz evoca al Jaime de la niñez o al Jaime de la juventud que deambulaba por los barrios o cuando se habla de los conocidos que murieron por complicaciones derivadas del sida, la cámara muestra a nińos corriendo en un parque o mojándose la cabeza debajo de una canilla o a jóvenes reuniéndose bajo un puente. En general, la yuxtaposición imagen-sonido no se corresponde necesariamente con lo que se dice. No hay una recreación dramatizada. Estas imágenes más bien habilitan vías nuevas de asociación con lo que se relata, una más conectada con el plano afectivo y la memoria personal del espectador.

Del mismo modo, Comedi reutiliza material de archivo registrado por su padre para intervenirlo y convertirlo, en algunos casos, en imágenes puramente hápticas. Es decir, la percepción visual y diferenciación de figuras se dificulta, hecho que obliga al espectador a observar las imágenes con otros sentidos en juego. Una de las secuencias recurrentes en el film de Comedi es el plano de un paisaje campestre capturado desde la ventana de un tren en movimiento. Pero dichos planos paulatinamente van perdiendo su referencia y devienen imágenes abstractas, de praderas desenfocadas o cielos abiertos que se confunden con el horizonte. Una vez que se relata la muerte de Jaime, el mismo prado aparece en un ritmo que imita la palpitación de un corazón y que va cambiando de color, de textura, a medida que avanza cada fotograma. Hacia el final del film, una secuencia breve captura imágenes sueltas de obreros trabajando en una construcción con la melodía de una cajita musical de fondo. Se ven los torsos desnudos de los hombres y una mano que abre y cierra su puño junto a un martillo depositado a su lado. Podría agregarse que también se utiliza un filtro que simula una captura hecha con $35 \mathrm{~mm}$. Más allá de las posibles lecturas alegóricas que se puedan hacer de estas imágenes, prevalece la atención sobre los cuerpos tensionados, el puño esforzándose por corresponderse con la pesadez 

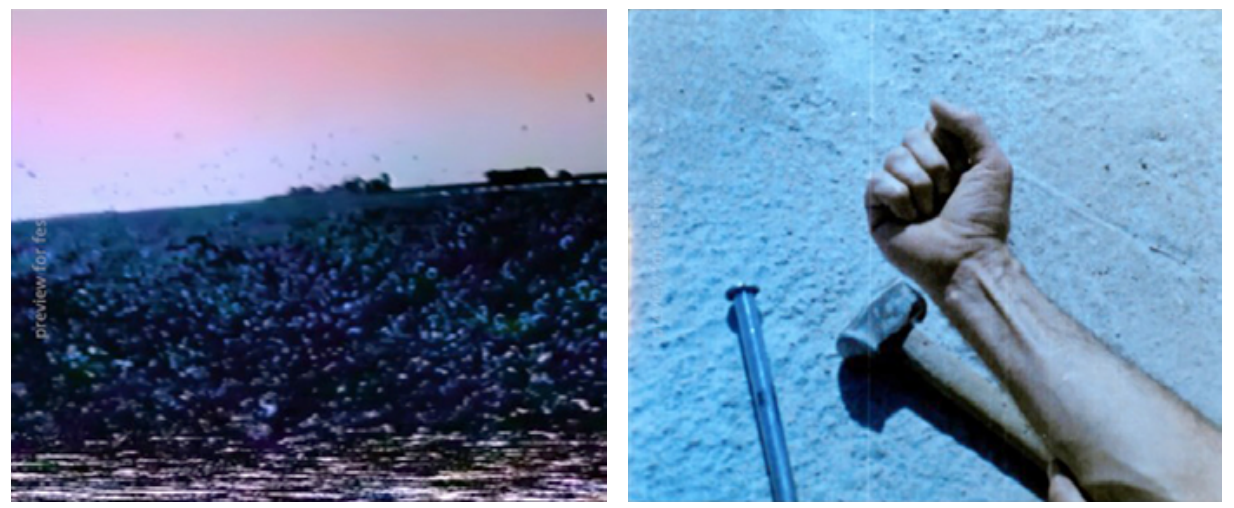

Fig. 5 y 6: Imágenes hápticas en El silencio es un cuerpo que cae.

de un martillo, la sensación de pasado o memoria que da como efecto el filtro de la cinta. Ya se trate de un ensayo en torno a la masculinidad impuesta sobre los cuerpos, el film apuesta a la hapticidad para detener la diégesis e invitar al espectador a observar la materialidad de la imagen. Lo mismo sucede con otra secuencia posterior en la que una mano recorre el cuerpo desnudo de una mujer embarazada mientras la directora cuenta el parto de su madre y la presencia del amante de Jaime. Como apunta Marks respecto al video Identical Time, de Seoungho Cho, pero que podría aplicarse al film de Comedi:

Unsure what he or she is seeing, the disoriented viewer suspends judgment [...], and tests the images by bringing them close. The viewer's vision takes a tactile relation to the surface of the image, moving over the figures that merge in the image plane as though faraway things are only an inch from one's body (181).

Estas intervenciones ofrecen una dimensión de percepción histórica diversa a la que ofrecen las entrevistas que Comedi intercala, por ejemplo. Las entrevistas hechas a personas allegadas a su padre (mujeres pertenecientes a un grupo político de izquierda, un conocido que vivió durante la época de la dictadura militar, una mujer trans que recuerda las fiestas que se organizaban, etc.) y las fotografías de la juventud de Jaime (de viaje con amigos o de veraneo en Córdoba) ofrecen referencias ópticas y verbales de lo que significó la vida de un hombre gay en los setenta y ochenta. Sin embargo, las imágenes intervenidas permiten una relación de tipo háptico con el espectador, en la que pueda reconstruirse (aunque sea precariamente) la afectividad pasada de un grupo desplazado por la historia oficial y, en particular, la de Jaime. Quizás sea tentador dilucidar qué tipos de afectos prevalecen en estas imágenes reconstruidas, pero esto sería imposible porque la relación intersubjetiva con el espectador y su memoria es evasiva, personal y, quizás, no del todo acertada o aprehensible por cualquiera. 
Tanto el film de Comedi como los de Aldarondo y Costa se esfuerzan en manifestar de manera audiovisual una memoria perdida, secreta u ocultada intencionalmente para borrar la presencia incómoda de una afectividad y sexualidad amenazantes. Estos lenguajes y recursos formales irrumpen en la progresión narrativa, distorsionan la percepción óptica y fuerzan al espectador a ser consciente de la materialidad de lo que se observa. En mayor o menor medida, los filmes de Aldarondo, Comedi y Costa buscan dar cuenta de una emoción y corporalidad evasivas que demandan estrategias drásticas, de quiebre, de fisuras elocuentes, que den espacio a una voz no-oficial y en un lenguaje más cercano a la fisicalidad de quien ve. Solo de esta manera puede lograrse lo que Cvetkovich rescata de los archivos del trauma: «they must enable the acknowledgment of a past that can be painful to remember, impossible to forget, and resistant to consciusness» (241).

Además, este ejercicio de memoria posibilita a las directoras una práctica autobiográfica, un ejercicio de autoentendimiento que transita lo traumático y cuyos vestigios seguramente permanecen hasta hoy. Según Michael Renov, la documentación de la vida de otros, especialmente si son miembros de la familia, sirve como espejo del yo (44). Cabe pensar los modos en que el yo-narrador de la directora se entrelaza con el yo-narrado que aparece con diferentes intensidades en cada film. Por un lado, en 108, la presencia de Renate Costa domina el film, tanto frente como detrás de cámara. No existe ningún archivo en el que Rodolfo hable por sí mismo. Sin embargo, la directora presenta la voz de su tío de forma indirecta a través de lo que otros dicen que él dijo. En el caso de Memories, Aldarondo hace uso de un sinfín de material producido por el mismo Miguel Dieppa y que evidencia una voz autobiográfica diferente a la de la directora. Aldarondo coloca clips de entrevistas hechas a Miguel en las que habla de su vida profesional en Nueva York y también utiliza la voz de un actor para reproducir fragmentos de cartas enviadas a Puerto Rico o incluso una obra teatral que habla de la isla. Aldarondo se pregunta constantemente qué pensaba él sobre su familia y su lugar de origen y utiliza estos materiales para responderse. Ya hacia el final del film, revela que estos cuestionamientos son los que ella se hace a sí misma, hacia lo que ella piensa sobre su familia. Incluso agrega, entre lágrimas, cuando le dice a su madre: «I'm realizing I'm here telling this story about all of these people and I'm struggling to figure out how do I forgive everyone. [...] Sometimes I feel I'm on a quest for justice on behalf of your little brother». Esta confluencia entre los yoes de Memories se contrapone a una tensión en los yoes de El silencio es un cuerpo que cae. Si bien Comedi cuenta con material filmado por su propio padre, no parece encontrar respuesta alguna, en este material, a los cuestionamientos que hace sobre su familia y la sexualidad de Jaime. El yo-narrador de Comedi resignifica el material producido por el yo-narrado de Jaime y en ese ejercicio relee su propia infancia. Gran parte del archivo filmado por su padre consiste en viajes familiares en los que la figura principal es la directora de niña. Podría proponerse que la búsqueda que hace es la de entender y entenderse en esa época familiar, sobre todo cuando afirma al principio del film que un amigo de su padre le dijo: «Cuando vos naciste, una parte de Jaime murió para siempre». Esta búsqueda parece tener fin hacia el final cuando la directora graba a su propio hijo en la cotidianeidad de su casa, en lo que parece ser una apuesta por la vida presente. 
El entramado de voces, de yoes, que aparece en los filmes merece un estudio más detenido. Sin embargo, esto permite ubicar los documentales dentro de lo que Leonor Arfuch denomina el espacio biográfico y que involucra no solo autobiografías o memorias, sino también productos mediáticos como talk-shows, entrevistas y reality shows (17). Los filmes de Aldarondo, Costa y Comedi evidencian los cuestionamientos de Arfuch a la autenticidad y univocidad del yo en su acto de inscripción. ¿Cómo discernir el carácter autobiográfico de estos filmes -el relatar el yo mismosin necesariamente narrar a otro yo? Al referirse a la biografía, Arfuch enfatiza el valor comunal de los textos, la relación del sujeto con su entorno, su familia, su linaje: «la contemplación de la vida de uno será tan solo 'una anticipación del recuerdo de otros' acerca de esa vida, recuerdo de descendientes, parientes y allegados» (108).

Finalmente, conviene resaltar de estos filmes su práctica autobiográfica, que consiste en un retrato propio refractado a través de un otro-familiar, ya sea tío o padre. La corporalidad de los sujetos ausentes que se reconstruye de diferentes modos no solo sirve para acercarlas a los espectadores a modo de denuncia o crítica política al discurso dominante en la familia o la Iglesia, sino sobre todo para combatir la nostalgia y el trauma de la pérdida de un ser querido. 


\section{REFERENCIAS}

Aldarondo, Cecilia, directora. Memories of a Penitent Heart. Blackscrackle Films, 2016.

Andermann, Jens. New Argentine Cinema. New York: I.B. Tuaris \& Co, 2011.

Arfuch, Leonor. El espacio biográfico. Dilemas de la subjetividad contemporánea. Buenos Aires: Fondo de Cultura Económica, 2007.

Ciancio, Belén. «Ante el límite de la representación en el documental: cuerpo filmado, filmado-hablante, filmante, (anti)espectante». HeLix, 10 (2017), pp. 234-256.

Comedi, Agustina, directora. El silencio es un cuerpo que cae. El Calefón Cine, 2019.

Costa, Renate, directora. 108 Cuchillo de palo. Icarus Films, 2010.

Cvetrovich, Ann. An Archive of Feelings: Trauma, Sexuality, and Lesbian Public Cultures. Durham: Duke University Press, 2003.

Fiore Urízar, Rafaela y Holt, Chloe. «Salidas del armario: Políticas de miedo y violencia contra la comunidad gay en el documental paraguayo 108 Cuchillo de palo», en Bilbija, Ksenija, Fornicito, Ana y Llanos, Bernardita (eds.), Poner el cuerpo: Rescatar y visibilizar las marcas sexuales y de género de los archivos dictatoriales del Cono Sur. Santiago de Chile: Cuarto Propio, 2017, pp. 241-259.

KydD, Elspeth. «Looking for Home in Home Movies: The Home Mode in Caribbean Diaspora First Person Film and Video Practice», en Lebow, Alisa (ed.), The Cinema of Me: The Self and Subjectivity in First Person Documentary. Nueva York: Columbia University Press, 2012, pp. 183-200.

Machuca-Gálvez, Milton. «Memories of a Penitent Heart by Cecilia Aldarondo (review)». Hispania. 101:3 (2018), pp. 480-481.

Marks, Laura. The Skin of the Film. Intercultural Cinema, Embodiment, and the Senses. Durham: Duke University Press, 2000.

Piedras, Pablo. El cine documental en primera persona. Buenos Aires: Paidós, 2014.

Renov, Michael. «First-person Films. Some Theses on Self-Inscription», De Jong, Wilma y Austin, Thomas (eds.), Rethinking Documentary: New Perspectives, New Practices. New York: Open University Press, 2008, pp. 39-51.

Romero, Eva K. Film and Democracy in Paraguay. Cham: Palgrave, 2016.

Sовснаск, Vivian. The Address of the Eye. A Phenomenology of Film Experience. Princeton: Princeton University Press, 1992.

Soвснаск, Vivian. «The Scene of the Screen: Envisioning Cinematic and Electronic 'Presence'», Karl Ludwig Pfeiffer y Hans Ulrich Gumbrecht (eds.), Materialities of Communication. Stanford: Stanford University Press, 1994, pp. 83-106.

Vidal-Ortiz, Salvador. «Memories of a Penitent Heart». Latino Studies, 17 (2019), pp. 421-423. 